\title{
CALCULATING THE MODULI ELASTICITY FOR REINFORCED CONCRETE USING NEW RULE OF MIXTURES APPROACH FOR THE DAM STRUCTURE
}

\section{Zainordin Firdaus Zulkefli ${ }^{2}$, Mohd Hafiz Zawawi ${ }^{1}$, Nurul Husna Hassan ${ }^{2}$, Mohd Remy Rozainy Mohd Arif Zainol ${ }^{2 *}$, Mohamad Aizat Abas ${ }^{3}$ and Ahmad Zhafran Ahmad Mazlan ${ }^{3}$}

${ }^{1}$ Department of Civil Engineering, College of Engineering, Universiti Tenaga Nasional, Selangor,

${ }^{2}$ School of Civil Engineering, Engineering Campus, Universiti Sains, Malaysia, Penang

${ }^{3}$ School of Mechanical Engineering, Engineering Campus, Universiti Sains, Malaysia, Penang

*Email: ceremy@usm.my

\begin{abstract}
Dam is the important structure use for water domestic store, electricity power supply, irrigation and flood control. Dam deal with reinforced concrete as a main material in construction. The material considerable safe when ability to support external and internal load. The capability of dam material due to safety is effect by degradation. Prevention monitoring must be conducted for high risk structure. Thus, moduli elastic is a mechanical property to measure stiffness and had relationship between stress and strain of material. While non-destructive and destructive testing in site inspection does not include reinforce and give incorrect moduli elasticity. New approach rule of mixture (Rom) with solid work software refer to United States Department of the Interior Bureau of Reclamation (USBR) standard design for small dam, give reliability monitoring with true sustain modulus elasticity of dam structure time by time. The concrete properties for sustain of moduli elasticity standard type gravity concrete dam value is $20.684 \mathrm{GPa}$. If the value decreases drastically from the standard, high precaution must be taken.
\end{abstract}

Keywords: Dam, safety, prevention monitoring, reinforced concrete, destructive, nondestructive, rules of mixture (Rom), solid work, and USBR standard and moduli elasticity.

\section{INTRODUCTION}

Dam are infrastructure provide service to public for long term with economy value. Expend service of life these infrastructures with preventive and corrective maintenance continuously. The dam are consider in failure mode if cannot containment the water at upstream. Dam failure can cause fatality, property damage, water supply disruption and other negative impact. A dam must construct with concrete material where ability to sustained loading, thus concrete properties must have criteria such as strength, permeability, durability and other properties [1]. Therefore, the dam must always put in safety condition. Monitoring can be done toward observation and inspection. Destructive tests are the method where the sample or specimen is crushing to get 
information about strength and stress strain by using mechanical machine. Destructive testing using small concrete core with diameter $50 \mathrm{~mm}$ because it gives very small damage and avoid cutting the reinforcement of the structure [2]. Meanwhile nondestructive test where the devices is use directly to the structural to estimate the strength of concrete without damage the structure [3]. This study was conducted to determine reliable sustain moduli elasticity using new approach rule of mixture, difference between moduli elasticity (new approach) and moduli elasticity (normal practice). Minimum value for dam concrete material properties refer to United States Department of the Interior Berau of Reclaimation Design of Small Dams (USBR) shown in Table 1.

Table 1. Clause 8.4 (b) criteria concrete material for dam [4]

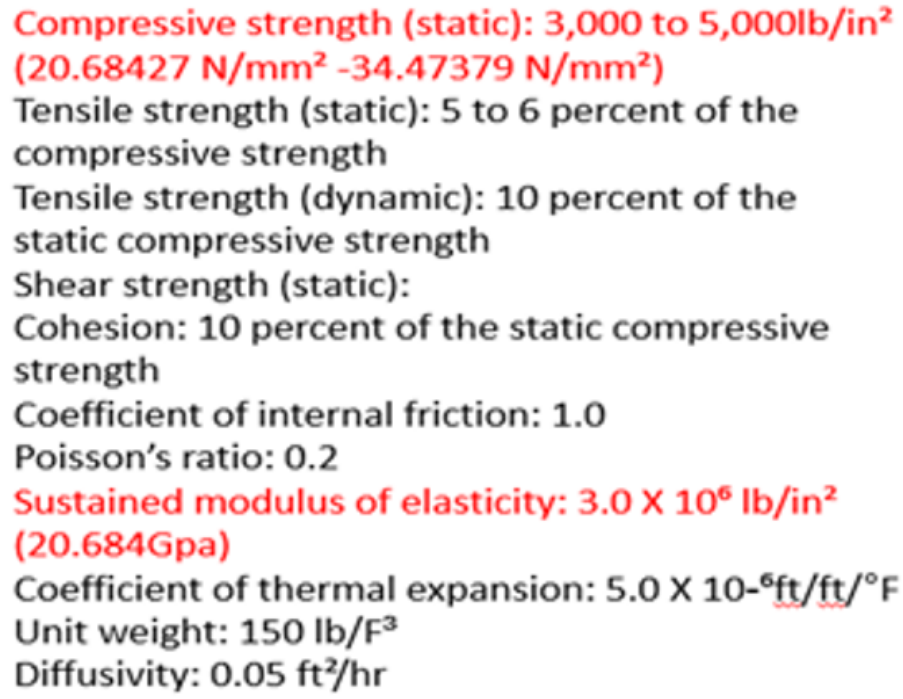

As shown in Table 1, compressive strength is between $20.684 \mathrm{~N} / \mathrm{mm}^{2}-34.474 \mathrm{~N} / \mathrm{mm}^{2}$. While sustained modulus elasticity is $20.684 \mathrm{GPa}$. Rule of mixtures is suitable formulae for composite material such reinforcement concrete in term to determine modulus elasticity [5]. The standard practice not counting reinforcement value to determine sustain moduli elasticity. Modification approach of Rules of mixture (Rom) is to get true value of moduli elasticity for current dam monitoring.

\section{METHODOLOGY}

\section{Experimental Procedure}

If the dam necessary to core use destructive test. Core the dam structure $(50 \mathrm{~mm}$ diameter) for the section had a problem or critical and label the location of specimen, then cutting the specimen $\mathrm{L} / \mathrm{D}=2$ (Standard) [6], measure the diameter and height of specimen, next key in the value diameter and height of specimen into compression software, setup the graph stress strain, lastly start to compress until sample crush and failure. Provide stress strain graph results for next step for modulus elasticity 
calculation. If the risk is too high dam core is not aloud, use nondestructive to produce stress strain results for modulus elasticity calculation.

\section{Moduli Elasticity Calculation}

The $E$ value without reinforcement can be calculated using the following equation:

$E_{\text {normal practice }}=\sigma / \mathcal{E}$

$E$ normal practice is without reinforcement, concrete only $\sigma / \varepsilon$ (From compression test results)

Rule of mixtures (Rom) [7]

$E_{\text {new approach }}=\left[\left(E_{\text {concrete }}\right)\left(V_{\text {concrete }} / V_{\text {total }}\right)\right]+\left[\left(E_{\text {steel }}\right)\left(V_{\text {steel }} / V_{\text {total }}\right)\right]$

$E_{\text {concrete }}=$ modulus for concrete

$E_{\text {steel }}=$ modulus for reinforcement

$E_{\text {new approach }}=$ combination concrete with reinforcement

$V_{\text {concrete }}=$ Volume of friction of concrete from solid work software

$V_{\text {steel }}=$ Volume of friction of reinforcement from solid work software

Volume friction of reinforcement can be determined by draw back reinforcement into SolidWorks software refer to original as built drawing. Select the critical path of the dam. SolidWorks can generate volume information shown in Figure 1.

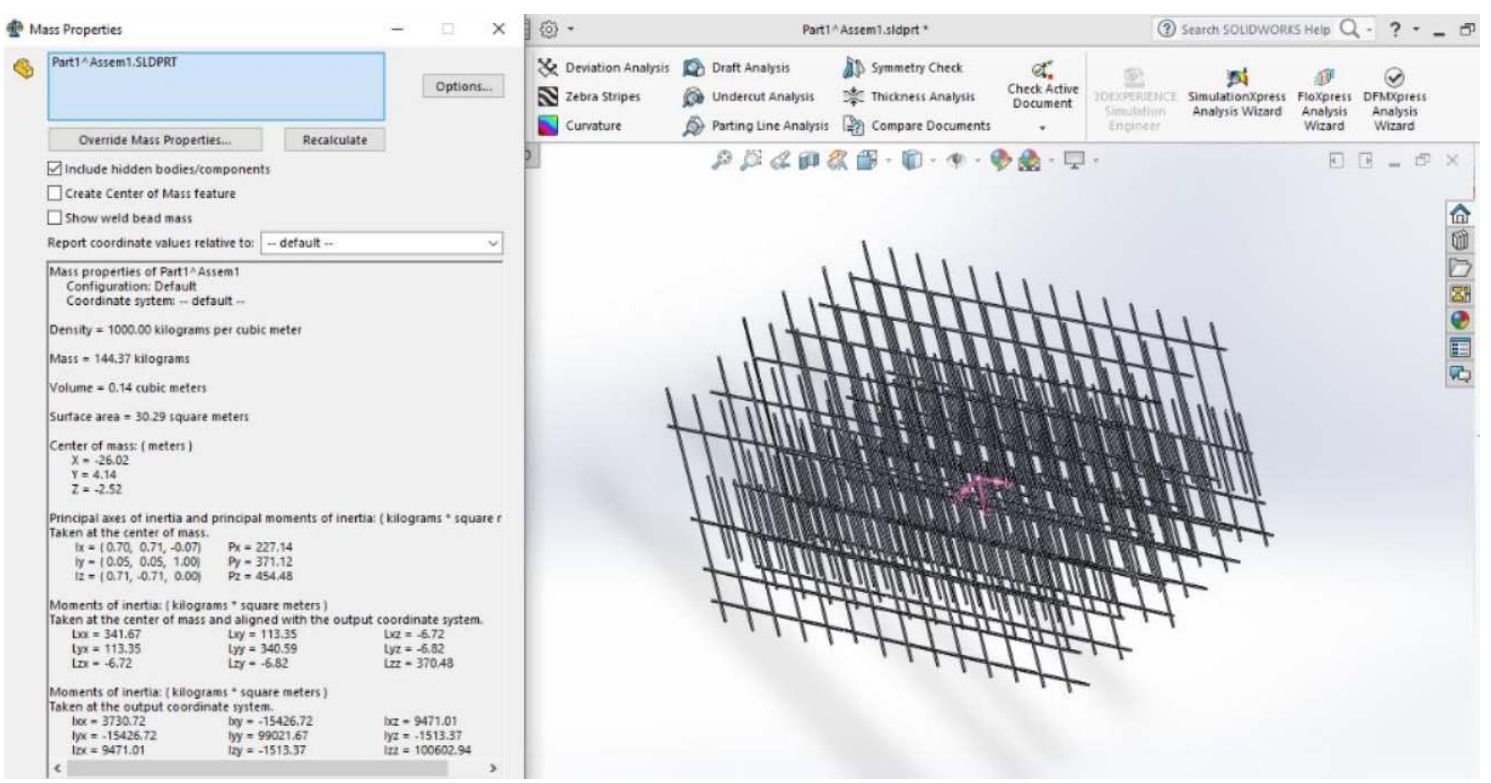

Figure 1: SolidWorks generate volume friction of reinforcement from the drawing.

SolidWorks give detail output volume of friction for reinforcement and details of information in mass properties shown in Figure 2 


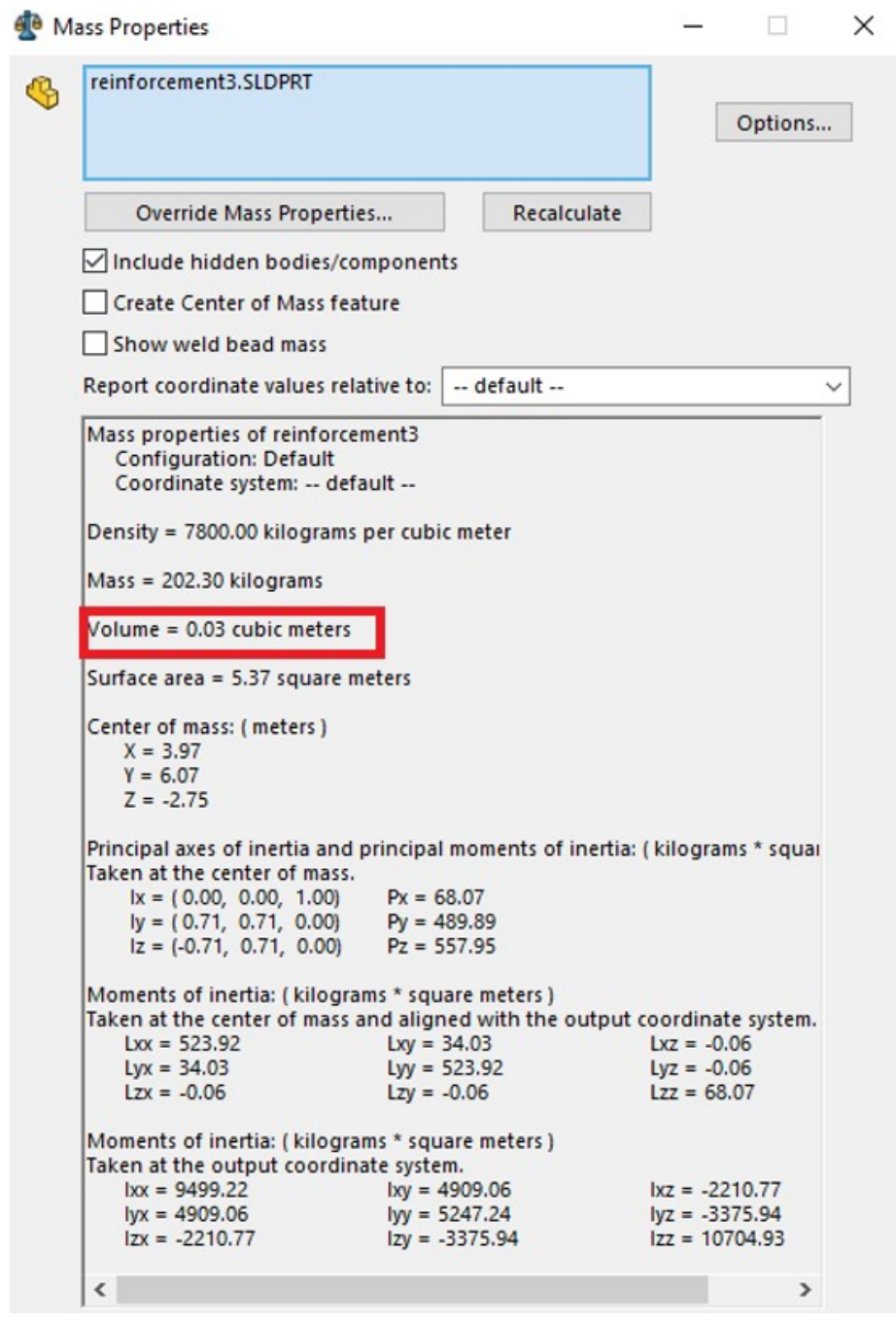

Figure 2: Mass properties of SolidWorks.

Volume friction of concrete also can be defined, draw back shape part of dam in solid work software shown in figure 3 , insert density value of concrete with correct ratio. Make sure that all dimension is correct.

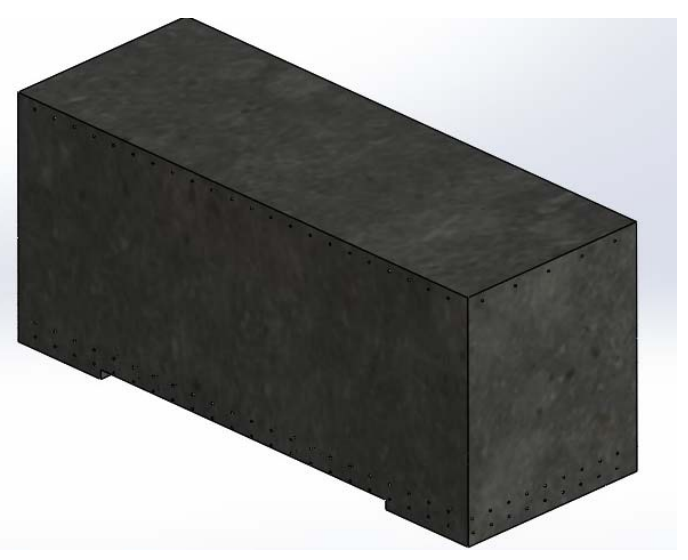

Figure 3. Volume friction of concrete in SolidWorks software 


\section{RESULTS AND DISCUSSION}

In this section, the result show difference between moduli elasticity (normal practice) and moduli elasticity (new approach) shown in Table 2. The higher difference is 5.41 $\mathrm{GPa}$ and the lowest difference is $3.65 \mathrm{GPa}$. The average of difference is $4.45 \mathrm{GPa}$.

Table 2. Difference between moduli elasticity (normal practice) and moduli elasticity (new approach).

\begin{tabular}{|c|c|c|c|}
\hline Specimen & $\begin{array}{c}\text { Moduli elasticity } \\
\text { (Normal practice), GPa }\end{array}$ & $\begin{array}{c}\text { Moduli elasticity } \\
\text { (New approach), GPa }\end{array}$ & $\begin{array}{c}\text { Difference, } \\
\text { GPa }\end{array}$ \\
\hline 1 & 21.94 & 26.81 & 5.41 \\
\hline 2 & 21.17 & 25.73 & 4.56 \\
\hline 3 & 20.11 & 24.89 & 4.78 \\
\hline 4 & 20.13 & 23.78 & 3.65 \\
\hline 5 & 19.14 & 22.97 & 3.83 \\
\hline
\end{tabular}

\section{CONCLUSION}

In this study, the main objective to determine true value moduli elasticity using new approach of Rule of mixture (Rom). Table 3 shows result of moduli elasticity new approach compare to sustain moduli elasticity USBR(standard). All specimen are not exceed $20.684 \mathrm{GPa}$. The difference must not ignore because the value in GPa consider big. If the value estimating is over, it will affect the cost of material such as decrease of bar reinforcement, decrease size of bar, decrease of mixing ratio of concrete. If the estimating value is less, the situation always in failure but reality condition is safe. The best practice is getting the true value. Monitoring can be done accurately.

Table 3. Result of moduli elasticity new approach compare to sustain moduli elasticity USBR (Standard).

\begin{tabular}{|c|c|c|}
\hline Specimen & $\begin{array}{c}\text { Moduli elasticity } \\
\text { (New approach } \\
\text { practice), GPa }\end{array}$ & $\begin{array}{c}\text { USBR } \\
\text { Sustain moduli } \\
\text { elasticity, GPa }\end{array}$ \\
\hline 1 & 26.81 & \multirow{2}{*}{20.68} \\
\hline 2 & 25.73 & \multirow{2}{*}{} \\
\hline 3 & 24.89 & \\
\hline 4 & 23.78 & \\
\hline 5 & 22.97 & \\
\hline
\end{tabular}




\section{REFERENCES}

[1] Bakenaz A. Zeidan(2014). "Design and analysis of concrete gravity dam".Article Review.Tanta University.

[2] Yamamoto, H. Hamada, Y. Sagawa, and T. Hiromitsu, "Evaluation of compressive strength of concrete using small diameter core.”

[3] Samia Hannachi and M Nacer Guetteche. Review of the rebound hammer method, estimating concrete compressive strength on the site.

[4] United States Department of the Interior Berau of Reclaimation Design of Small Dams (USBR).

[5] G. R. Liu, "A step-by-step method of rule-of-mixture of fiber- and particlereinforced composite materials,” Composite structure vol. 40, pp. 313-322, 1998.

[6] S. Suzuki, T. Kage, and S. Seko, "Influence that Ratio of Length to Diameter of High-Strength Concrete Core to Compressive Strength of Concrete,” pp. 1-8.

[7] A.S. Ezeldin, P.N. Balaguru, Normal and high-strength fiber-reinforced concrete under compression, Journal of Materials in Civil Engineering 4 (4) (1992) 415429. 